\title{
UN HIMNO ÓRFICO FRAGMENTARIO
}

\author{
Alberto Bernabé \\ Profesor Emérito Universidad Complutense de Madrid \\ (Instituto Universitario de Ciencias de las Religiones) \\ albernab@ucm.es
}

\section{RESUMEN}

Clemente de Alejandría cita en Stromateis 5.14.116.1 y 125.1 dos pasajes hímnicos atribuidos a Orfeo. Uno, más extenso, formaba parte de un himno a Zeus muy semejante en forma y contenido a los de la colección tardía de Himnos órficos. El otro, un solo verso, parece el comienzo de un Himno a Crono, influido por un mito de las teogonías órficas. El propósito del artículo es traducir y comentar ambos fragmentos, y examinar tanto sus aspectos formales, como la ideología religiosa que traslucen, como muestras de un tipo de obras literarias características del orfismo tardío. Asimismo se discute la posibilidad de que pertenezcan al mismo himno.

Palabras Clave: Poesía órfica, Clemente Alejandrino, Himnos, Zeus, Crono.

\section{A FRAGMENTARY ORPHIC HYMN}

\section{ABSTRACT}

Clement of Alexandria quotes in Stromateis 5.14.116.1 and 25.1 two hymnical passages attributed to Orpheus. One, more extensive, was part of a hymn to Zeus very similar in form and content to those of the late collection of Orphic Hymns. The other, a single verse, seems to be the beginning of a Hymn to Kronos, influenced by a myth of the Orphic theogonies. The purpose of the article is to translate and comment on both fragments, and to examine both their formal aspects, and the religious ideology they convey, as samples of a type of literary work characteristic of late Orphism. It also discusses the possibility that they belong to the same hymn.

KeYwOrds: Orphic poetry, Clemens Alexandrinus, Hymns, Zeus, Kronos.

\section{DOS PASAJES HÍMNICOS ATRIBUIDOS A ORFEO}

Clemente de Alejandría cita en dos lugares próximos de sus Stromateis sendos pasajes hímnicos atribuidos a Orfeo, uno de dieciséis versos y otro de un solo verso, con el propósito de aportarlos como testimonios a su propósito apologético. En este trabajo no voy a ocuparme de la función de los pasajes en la estrategia del Padre 
de la Iglesia (Herrero, 2010: 190-196), sino de examinar estas piezas literarias, como tales, y comentar sus contenidos, para tratar de situarlas en su contexto originario: la tradición órfica tardía. Se ha propuesto que ambos pertenecían al mismo himno y si efectivamente es así, el fragmento consistente en un solo verso sería probablemente el primero del poema, aunque tal afirmación no está exenta de problemas ${ }^{2}$. Por ello he considerado preferible comenzar con el pasaje más largo para, una vez analizado, ver luego si el de un solo verso puede o no ser atribuido a la misma obra.

\section{FRAGMENTO DE UN HIMNO A ZEUS: TEXTO Y TRADUCCIÓN}

El pasaje de dieciséis versos ${ }^{3}$ es citado por Clemente como un paralelo de Orfeo a las Sagradas Escrituras, y lo introduce con una alusión a Isaías. Luego interrumpe la cita con una observación sobre su presunto contenido, lo que le permite seguramente obviar algunos versos del poema que no le interesaban para su propósito, y luego cita lo que claramente es el final del himno.

El texto, incluidos los añadidos clementinos, es el siguiente ${ }^{4}$ :

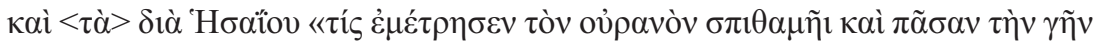

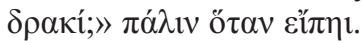

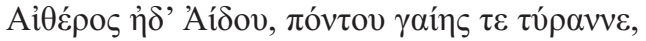

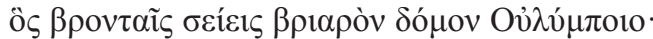

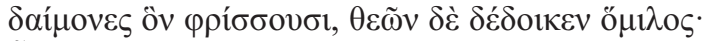

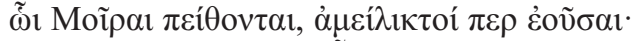

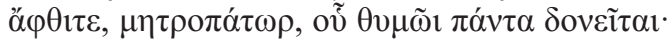

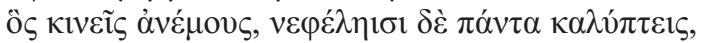

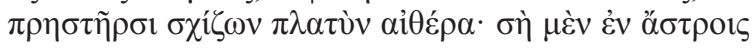

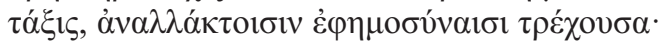

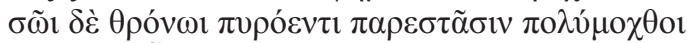

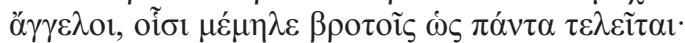

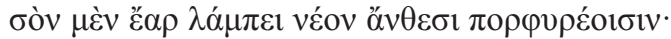

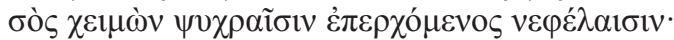

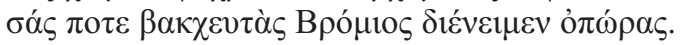

${ }^{1}$ Clem. Al. Strom. 5.14.116.1 y 5.14.125.1 (este último, reproducido por Eus. PE 13.13.52).

${ }^{2}$ Cf. el apartado $\$ 5$.

${ }^{3}$ Clem. Al. Strom. 5.14.125.1

${ }^{4}$ El texto es el del fragmento 691 de mi edición de los fragmentos órficos (Bernabé, 2004-2005), a la que me referiré a partir de ahora como $O F$ seguido del número de fragmento con el que se recogen en ella. No haré alusión a variantes o propuestas alternativas, que pueden encontrarse en el aparato crítico de la citada edición. Allí podrán hallarse, asimismo, con mayor detalle loci similes de cada verso, ya que en este artículo me he limitado a los más relevantes. Los pasajes habían sido editados antes por Kern (1922: F 248 y 338). Para las referencias a los Himnos órficos usaré OH seguido de los números de himno y verso. 


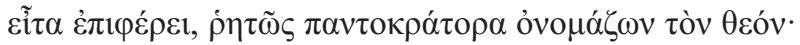

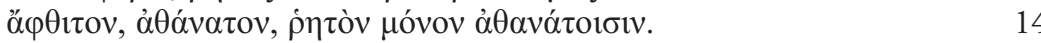

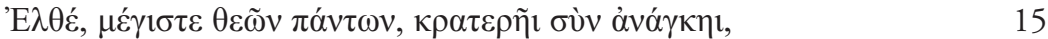

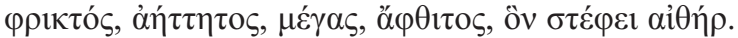

Y él (sc. Orfeo habla) a través de Isaías (40.12): ‘QQuién ha medido el cielo con su palmo y toda la tierra con un puñado?' cuando dice:

Del Éter y del Hades, del mar y de la tierra soberano, que con truenos agitas la firme morada del Olimpo,

ante el que los démones se estremecen, y de los dioses se aterra la asamblea, al que las Moiras obedecen, por implacables que sean,

imperecedero, madre-padre, ante cuya cólera todo se ve sacudido,

que impulsas los vientos y con nubes todo lo cubres,

que con los rayos hiendes el anchuroso éter; tuya es en los astros

la formación, que con inmutables mandatos se desplaza.

Ante tu trono ígneo comparecen muy atribulados

mensajeros, a los que importa que a los mortales todo se les cumpla,

tuya, la primavera resplandece, nueva, con sus flores de púrpura,

tuyo, el invierno, con gélidas nubes sobreviene,

tuyos, los frutos que antaño el báquico Bromio dispensó.

Y luego añade, llamando expresamente todopoderoso a Dios 5 :

indestructible, inmortal, expresable solo por los inmortales.

Acude, el más grande de los dioses todos, con poderosa necesidad,

estremecedor, invencible, grande, imperecedero, a quien corona el éter.

\section{FRAGMENTO DE UN HIMNO A ZEUS: COMENTARIO}

El verso 1 se inicia con Aîtépos, la parte más alta del universo, en la concep-

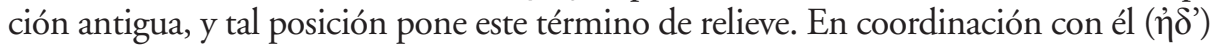
y formando una primera pareja de ámbitos del espacio en vertical, 'Aíoov, se refiere polarmente al ámbito inferior del mundo. En asíndeton con la primera, se muestra

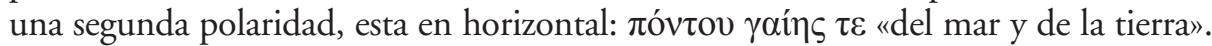
Los cuatro genitivos dependen del vocativo $\tau u ́ \rho \alpha v v \varepsilon$, que no tiene el sentido peyorativo que el término tendría en la Atenas clásica, sino que se sitúa en una tradición en la que la expresión designa simplemente un monarca absoluto, sin connotación alguna de ilegitimidad ${ }^{6}$. Así pues, las dos polaridades espaciales, la vertical

${ }^{5}$ Como señala Herrero, 2010: 191 عĩ் $\alpha$ sugiere que Clemente ha omitido una parte. También indica que la razón de que Clemente afirme que el autor del himno le llama expresamente $\pi \alpha v \tau o \kappa \rho \alpha ́ \tau \omega \rho$

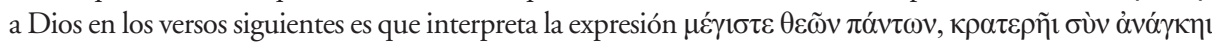
como un juego de palabras etimológico. Ver Herrero l. c. para otros detalles de la adaptación de Clemente.

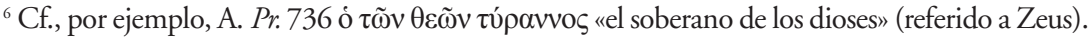


y la horizontal determinan el enorme marco sobre el que se ejerce el poder del dios, el ámbito de la totalidad del universo, frente al carácter parcial que habitualmente tiene el poder de los dioses griegos, circunscrito a ámbitos más concretos.

El verso 2 es introducido por un relativo en nominativo, forma muy característica en los himnos, tras una invocación, para desarrollar aspectos de la divinidad. En efecto se mencionan los rasgos más característicos del dios que ha sido invocado como monarca del universo: el control del rayo y su posición en el Olimpo, sede y representación del poder divino. Todo ello apunta claramente, sin nombrarlo, a Zeus.

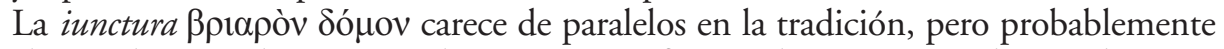
el autor ha querido jugar con las resonancias fónicas de $\beta \rho-o v \tau \alpha \tilde{\varsigma} \varsigma$ (el arma de Zeus) y $\beta \rho$-1 $\alpha \rho o ́ v$ usado por Homero, pero en un contexto diferente ${ }^{7}$. El verbo de la frase va en segunda persona $\left(\sigma \varepsilon i ́ \varepsilon 1 \varsigma^{8}\right)$, con lo que se establece una relación más directa

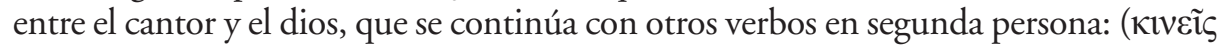

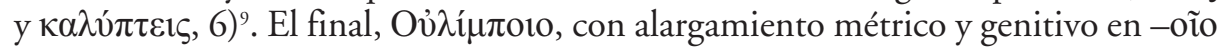
le presta al verso un fuerte tono homérico.

En el verso 3 un nuevo relativo, esta vez en acusativo y situado en segunda posición de la frase, cambia la perspectiva del discurso que, en lugar de centrarse en el dios invocado, pone el foco en la reacción que este produce en las demás divinidades. Tal reacción se presenta como un paralelismus membrorum, la misma idea en dos expresiones equivalentes que se refuerzan por insistencia -un procedimiento muy característico de literaturas orientales-. Los dioses son calificados primero con el antiguo cuasisinónimo $\delta \alpha i ́ \mu o v \varepsilon \varsigma^{10}$ y con la expresión $\theta \varepsilon \tilde{\omega} v$... ö $\mu \imath \lambda o \varsigma_{\text {. Esta }}$ última aparecía ya, con otro verbo, pero en la misma sedes metrica en un himno homérico antiguo ${ }^{11}$. La reacción de las divinidades se expresa por dos verbos, el primero, el muy gráfico $\varphi \rho i ́ \sigma \sigma o v \sigma l$ 'se estremecen' en un uso transitivo tan antiguo como Homero $^{12}$, el segundo, un verbo usual para expresar el temor, $\delta \varepsilon i ́ \delta \omega$, pero formulado en perfecto de estado, $\delta \varepsilon ́ \delta$ oı $\varepsilon v$, lo que indica que el temor de los dioses ante Zeus no es un sentimiento pasajero, sino una situación permanente.

El verso 4 se abre con otro relativo, esta vez en dativo, régimen de $\pi \varepsilon i ́ \theta o v \tau \alpha 1$,

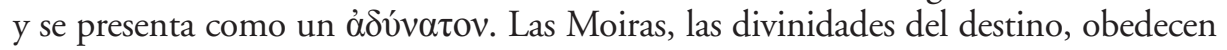

${ }^{7}$ Il. 11.375, 16.413, 18.611 para calificar un casco.

${ }^{8}$ El verbo es tradicional, no referido al Olimpo, pero sí en contextos en que hay referencias

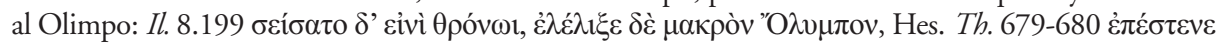

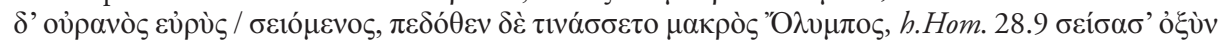

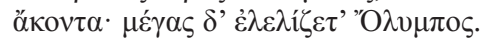

${ }^{9}$ Así como con el uso de adjetivos posesivos en segunda persona, en vv. 7-13.

${ }^{10}$ Sobre los démones cf. Suárez de la Torre, 2000, Sfameni Gasparro, 2015, Bernabé, en

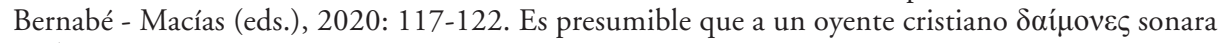
a «demonios».

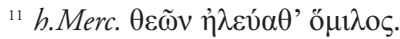

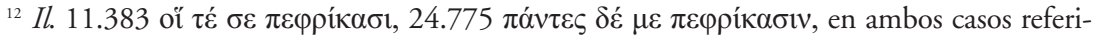
do a sentimientos humanos, provocados por humanos. 


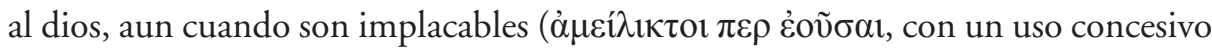
de $\pi \varepsilon \rho$ ya conocido desde Homero $^{13}$ ), lo que pone de relieve la autoridad ilimitada e irresistible de Zeus.

En el verso 5 se le aplica al dios el epíteto, ő́ $\varphi \imath \tau \varepsilon . ~ \alpha ̋ \varphi \theta \imath \tau o \varsigma$ es un cuasisinó-

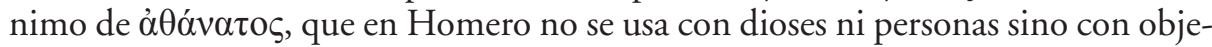
tos o abstractos, casi siempre de los dioses, con el sentido de «indestructible»" . Hesíodo lo refiere a una divinidad que es casi un lugar, $\Sigma \tau v^{\prime} \xi^{15}$, y en el Himno homérico a Hermes se usa unido a $\dot{\alpha} \theta \alpha \dot{v} \alpha \tau \mathrm{c} \varsigma$, en una expresión redundante, para referirse a los dioses como conjunto ${ }^{16}$. En los himnos órficos de la colección se usa cuatro veces, dos de ellas, calificando a dioses, en vocativo, como aquí1 ${ }^{17}$.

El uso de $\mu \eta \tau \rho \tau^{\prime} \alpha \dot{\tau} \omega \rho$ es muy interesante (Des Places, 1983: 382 n. 1). La palabra significaba «abuelo materno» y está documentada en ese sentido ya desde Homero ${ }^{18}$, pero en el poema su significado es claramente "madre-padre», es decir, que es padre y madre a la vez ${ }^{19}$. La expresión se sitúa en la línea de una alusión hímnica que ya se encontraba en el Himno a Zeus, de las Rapsodias ${ }^{20}$ o ya antes en forma larvada, en el Himno del Papiro de Derveni ${ }^{21}$, cuando se dice que, después de haber engullido el falo de Cielo (Urano) y haber hecho una en su propio cuerpo toda la creación, Zeus $\mu$ ท́ $\sigma \alpha \tau o$ los diferentes seres, tanto dioses como realidades físicas, como la Tierra, el Cielo, el Océano, esto es, las "concibió", no solo intelectual, sino físicamente, al darles de nuevo el ser de su propio cuerpo.

A continuación, en el mismo verso, oṽ introduce el único caso del relativo que aún no había sido usado, el genitivo, regido por el dativo $\theta v \mu \tilde{\omega}$ para describir la sacudida universal que produce la cólera del dios.

Los versos 6 a 8 expresan rasgos característicos, incluso tópicos, de un dios de los fenómenos atmosféricos como es Zeus: provocar el viento, cubrirlo todo

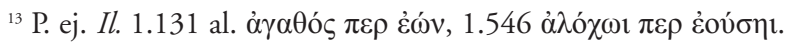

${ }^{14}$ Las llantas del carro de Hera (Il. 5.724), un trono fabricado por Hefesto (Il. 14.238), la casa del propio Hefesto (Il. 18.370), o abstractos como las ideas de Zeus (Il. 24.88). Una excepción sería el cetro de Agamenón (Il. 2.46), pero el poder de los reyes representado por el cetro viene de los dioses, según la concepción homérica.

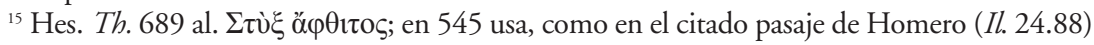

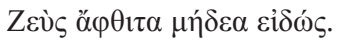

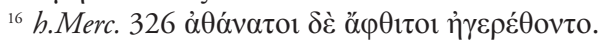

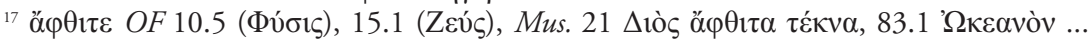
$\pi \alpha \tau \varepsilon \rho^{\prime}$ ö $\varphi \theta \imath$ itov. Sobre la colección, cf. Ricciardelli, 2000.

${ }^{18}$ Il. 11.224.

${ }^{19}$ Cf. Herrero, 2010: 192 n.110, quien cita a Le Boulluec, 1981: ad loc., para señalar que en este pasaje expresa la noción de un primer creador increado, cf. Firm. Mat. De err. 5 praef:: Deus tu omnium pater pariter et mater. inmortal ninfa'.

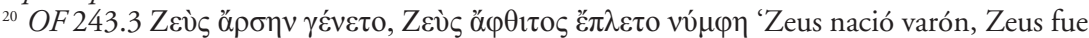

${ }^{21}$ OF 16. Sobre las versiones del himno a Zeus, cf. Bernabé, 2009. 
de nubes (desarrollando el antiguo epíteto homérico $v \varepsilon \varphi \varepsilon \lambda \eta \gamma \varepsilon \rho \varepsilon ́ \tau \alpha$ «amontonador de nubes $\left.\aleph^{22}\right)$ y hender el éter con sus rayos.

En cambio en los versos 7-8 se desarrolla una imagen interesante y novedosa,

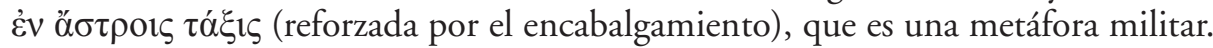
Los astros son descritos como un ejército bien adiestrado que se desplaza con movi-

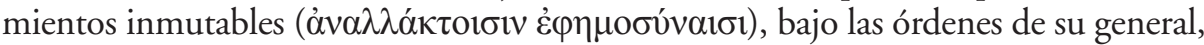

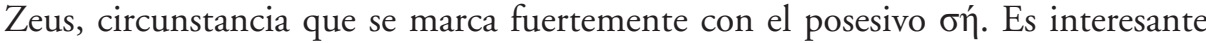
señalar que este posesivo es el primero de una serie, asimismo en géneros y casos diversos, que se despliega en los versos 9-13, para insistir en la idea, ya avanzada, de que el dios es dueño absoluto del universo.

El primero es $\sigma \tilde{\omega} 1$, concertando con $\theta \rho o ́ v \omega t$, el símbolo de poder regio. Siguen a este sintagma, en una notoria aliteración de labiales, tres términos: el primero, $\pi v \rho o ́ \varepsilon v \tau \imath$, que atribuye al trono una condición ígnea, como si se dotara a Zeus de una característica de los astros mismos; el segundo, $\pi \alpha \rho \varepsilon \sigma \tau \tilde{\alpha} \sigma \mathrm{v} v$, que abre de nuevo el punto de mira del poeta a los que están bajo el poder del dios y se presentan ante él, y el tercero, $\pi \mathrm{o} \lambda \hat{u} \mu \mathrm{o} \chi \mathrm{o}$, que con un nuevo encabalgamiento concierta con ä $\gamma \gamma \varepsilon \lambda o t$. Se trata de unos mensajeros encargados del cumplimiento de cuanto interesa a los mortales. Cabe preguntarse quiénes son estos mensajeros; probablemente una forma de llamar a los $\delta \alpha i ́ \mu o v \varepsilon \varsigma$, intermediarios entre la divinidad y los seres humanos, pero a los que evidentemente Clemente debió de considerar inmediatamente como «ángeles».

Los tres versos siguientes (11-13) iniciados por formas de posesivo, ponen de relieve que todo el transcurso del tiempo está en poder de Zeus: la primavera con el resplandor de sus flores (11), el invierno nuboso y frío (12) -la referencia a

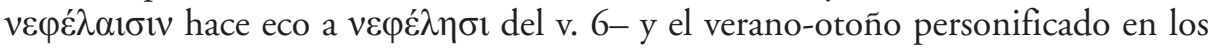

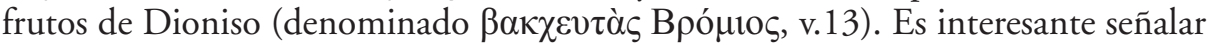
que Dioniso, de quien Zeus es padre y, según la tradición más extendida, también «madre» en cierto modo, ya que acabó su gestación en su propio muslo, a la muerte de Sémele, es como una especie de subordinado, que dispensa frutos, que no son suyos, sino de Zeus o, a lo más, como una suerte de alter ego del dios ${ }^{23}$.

Clemente interrumpe el himno, y probablemente omite algunos versos que no deberían resultarles interesantes para sus propósitos ${ }^{24}$. Retoma la cita del poema ya muy cerca del final, comenzando por un verso (14) en el que se reitera el adjetivo de la invocación del v. $5 \not ̋ \varphi \theta \imath \varepsilon \varepsilon$, ahora en acusativo, $\alpha \dot{\alpha} \theta \imath \tau o v$, que debía concertar con alguna referencia al dios en acusativo en el verso anterior perdido. No deja de ser curioso que el poeta emplee redundantemente con él el adjetivo ả $\theta \alpha ́ v \alpha \tau o v$,

\footnotetext{
${ }^{22}$ Il. 1.511 al.

${ }^{23}$ Sobre los dioses como avatar o alter ego de otros en la tradición órfica, cf. Bernabé, 2010.

${ }^{24}$ Cf. n. 5.
} 
como ocurría en el pasaje del Himno homérico a Hermes que antes he citado como paralelo ${ }^{25}$. Completa este verso, que recuerda muy de cerca, como los que siguen, los Himnos de la colección tardía, una referencia muy querida en la religiosidad tardía: el carácter indecible ("̋ $\rho \eta \tau o v)$ de la divinidad ${ }^{26}$, aquí expresado de una interesante

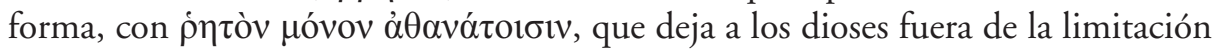
lingüística de los seres humanos para hablar del dios.

En los dos últimos versos se cierra el himno con una invocación a que el dios simplemente se presente, acompañada de una nueva serie de epítetos y expresiones que lo magnifican: su consideración como "el más grande de los dioses todos», "con poderosa necesidad», e insiste sobre epítetos ya expresados o redundantes:

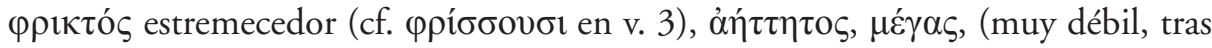

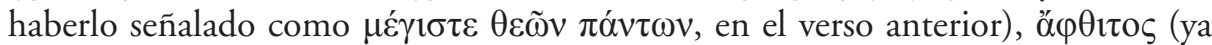

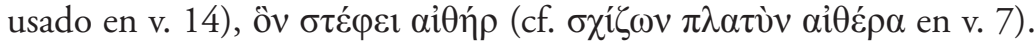

El himno, por su fraseología y el tipo de composición es muy semejante a los Himnos órficos de la colección. En cuanto al contenido, muestra las tendencias panteísticas y sincretistas del Helenismo. Aunque la obra no es judía ${ }^{27}$, son evidentes los influjos judíos y nósticos ${ }^{28}$.

\section{UN VERSO SOBRE CRONO}

El segundo fragmento objeto de este estudio es un verso, también atribuido a Orfeo por Clemente, en un pasaje en el que está aportando testimonios de autores griegos sobre la necesidad de postular un solo principio. Después de una cita de Homero $^{29}$, que considera una intuición sobre el Padre y el Hijo, añade ${ }^{30}$ :

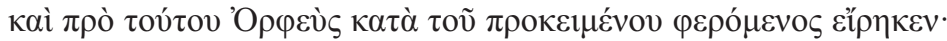

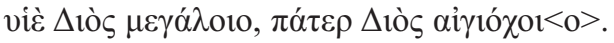

Y antes que él, Orfeo, al abordar la cuestión, dijo:

Hijo del gran Zeus, padre de Zeus egidífero.

${ }^{25}$ Cf. n. 16.

${ }^{26}$ Cf. OH 6.5 (Primogénito), 12.4 (Heracles), 30.3 (Dioniso), 32.3 (Atenea), 42.3 (Mise), 52.5 (Trietérico), cf. Bernabé, 2019: 142-144.

${ }^{27}$ Herrero, 2010: 192, quien argumenta, además, que Clemente conoce este himno a partir de una fuente no apologética.

${ }^{28}$ Cf. Herrero, 2010: 192 n. 109. Cf. además West, 1983: 36 n. 108, con loci paralleli de textos sincretísticos tardíos y Le Boulluec, 1981: ad loc.

${ }^{29}$ Od. 9.410-411, seguidos de 275.

${ }^{30}$ Clem. Al. Strom. 5.14.116.2 (OF 690). 
Formalmente, el verso se construye como un puzle sobre modelos muy tradicionales $^{31}$; en cuanto al contenido, la invocación en vocativo invita a considerarlo como la invocación inicial de un himno, en la que el poeta hace referencia a elementos identitarios del dios invocado. La frase se plantea, sin embargo, como una paradoja, ya que el dios es llamado, al mismo tiempo, hijo y padre de Zeus. Crono es el único dios del que se puede decir que es hijo y padre de Zeus. Que es padre de Zeus es una constante de la tradición ${ }^{32}$, pero no que sea su hijo. Sin embargo, la atribución del verso a Orfeo nos permite darle una explicación a la paradoja en el ámbito de la tradición mítica atribuida al bardo tracio ${ }^{33}$, única en la que se afirma que Crono, además de padre de Zeus, es luego su hijo: en la teogonía citada en el Papiro de Derveni Zeus engulle el falo de Urano y en las Rapsodias al dios Primogénito, Fanes; en ambos casos, como resultado de esta acción, Zeus, queda «embarazado» de todos los dioses y vuelve a darlos a luz, convirtiéndose de este modo en progenitor de todos ellos, una circunstancia que se refleja en un verso tan paradójico como el que aquí nos ocupa, y que se encuentra en diversas versiones de un himno a Zeus órfico ${ }^{34}$.

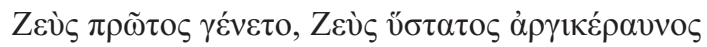

Zeus el primero nació, Zeus el último, el de rayo refulgente.

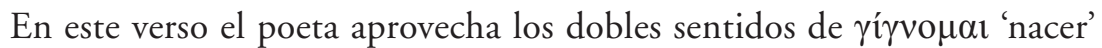

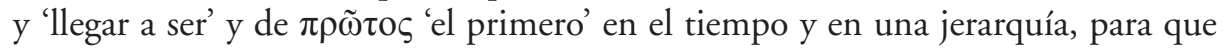
la paradoja pueda tener sentido: Zeus nació el último, ya que es hijo de Crono, y nieto de Urano, pero, tras engullir el falo de Urano (en la Teogonía de Derveni) o a Protógono (en la versión de las Rapsodias), llega a ser el primero, tanto porque ha hecho un bucle en el tiempo y en la línea generacional, de modo que los demás dioses nacen después de él, como porque se convierte en el soberano de los dioses. Así pues, se torna el primero tanto en sentido temporal como en sentido jerárquico.

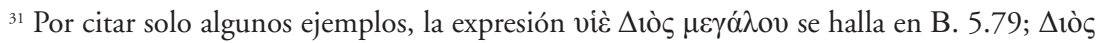

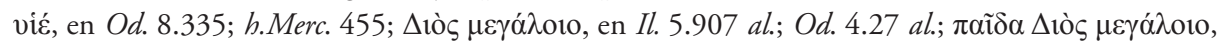

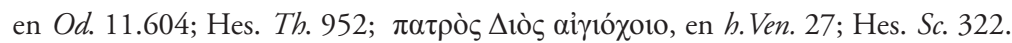

${ }^{32}$ Se afirma reiteradamente ya desde Homero y Hesíodo; baste recordar las fórmulas Zqù $\varsigma$

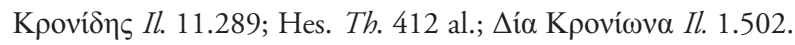

${ }^{33}$ West, 1983: 35 n. 107, que lo explica a la luz de las teogonías órficas. En mi edición de los fragmentos órficos lo edité, con dudas, como Himnus in Saturnum? Kern lo había editado en el apartado incertae sedis como fr. 38.

${ }^{34}$ OF 14, 31 y 243; cf. Bernabé, 2009. Cf. West, 1983: 35, quien cita $O H 8.13$ xpóvov

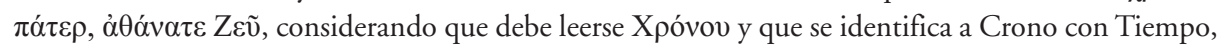
algo que en efecto sucede frecuentemente en época tardía. 
Cabe preguntarse dónde encontró Clemente el verso órfico (Herrero, 2010: 194). Le Boulluec (1981: ad loc.) piensa que es una «jewish forgery», lo cual me parece poco acertado por dos motivos: uno porque hablar de "forgery» en la poesía órfica es irrelevante: todo poema atribuido a Orfeo es producto de falsificación de un momento o de otro, ya que Orfeo no existió, sino que es un personaje mitológico. Y considerarlo judío es extraño si la atribución a Orfeo solo se explica para dar un sustento antiguo a la noción cristiana de Padre e Hijo, que no es en absoluto veterotestamentaria (Herrero, 2010: 194 n. 113). Es por tanto más probable que fuera un himno pagano, sincrético y tardío, aunque basado en la tradición de las Rapsodias, que sería luego utilizado por cristianos para defender la Trinidad con pasajes del «teólogo de los gentiles», Orfeo.

\section{5. ¿PROCEDEN AMBOS FRAGMENTOS DE LA MISMA OBRA?}

El fragmento más largo forma claramente parte de un Himno a Zeus, mientras que el verso inicial se refiere sin duda a Crono. Kern los editó como pertenecientes a obras distintas, pero West sugiere que se trata de pasajes del mismo himno ${ }^{35} \mathrm{y}$ en mi edición consideré la posibilidad de que lo fueran ${ }^{36}$. Herrero (2010: 194ss.) argumenta en favor de que pertenezcan al mismo himno, e incluso de que el verso $O F 690$ se refiera al mismo Zeus, que con su acto de recreación se convierte en su propio antecesor y su propio sucesor; los dos epítetos, siempre según Herrero, podrían indicar de un modo inefable, apropiado al género literario, sus dos reinos, el anterior y el posterior a la recreación. La cercanía de las citas de Clemente abogaría también por considerarlos fragmentos del mismo himno.

En suma, la pertenencia al mismo himno no puede ni afirmarse ni negarse, pero el hecho de que los cite el mismo autor, en contextos muy próximos y referidos ambos a Orfeo, y su situación en un entorno paradójico, característico del orfismo, que expresa por medio de tales paradojas la unidad que subyace a los diversos dioses y la idea de que en cierto modo son avatares o recreaciones de la única entidad divina, habrían hecho posible que Clemente acogiera favorablemente los dos pasajes como premoniciones paganas de la unidad y la omnipotencia de Dios.

\section{REFERENCIAS BIBLIOGRÁFICAS}

Bernabé, A. (2004-2005): Poetae Epici Graeci, Testimonia et fragmenta Pars II, fasc. 1-2, Orphicorum et Orphicis similium testimonia et fragmenta, Saur, Monachii et Lipsiae. OF 691)».

${ }^{35}$ West, 1983: 268 considera OF 690: «perhaps of the same hymn or collection as 248 (i.e.

${ }^{36}$ OF 691: «hymnus Iudaicus Alexandrinus, an idem atque fr 690?». 
Bernabé, A. (2009): «L'Inno a Zeus orfico. Vicissitudini letterarie, ideologiche e religiose», RFIC 137: 56-85 (versión en español, «El himno a Zeus órfico: vicisitudes literarias, ideológicas y religiosas», en A. Bernabé - F. CASAdesús - M. A. SAnTAMARÍa (eds.), Orfeo y el orfismo: nuevas perspectivas, edición online http://www.cervantesvirtual.com/obra/orfeo-y-el-orfismonuevas-perspectivas--0/.

Bernabé, A. (2010): «The Gods in Later Orphism», en J. N. Bremmer - A. Erskine (eds.), The Gods of Ancient Greece. Identities and Transformations, University Press, Edinbourgh, pp. 422-441.

Bernabé, A. (2019): La voz de Orfeo. Religión y poesía, UCO Press, Córdoba.

Bernabé, A. - Macías Otero, S. (eds.) (2020): Religión griega: una visión integradora, Guillermo Escolar, Madrid.

Des Places, É. (1983): Eusèbe de Césarée, La préparation évangélique, Livres XII-XIII, Les Éditions du Cerf, Paris.

Herrero, M. (2010): Orphism and Christinity in Late Antiquity, De Gruyter, Berlin/New York.

KERN, O. (1922): Orphicorum fragmenta, Weidmann, Berlin (21963, Dublin-Zürich 1972).

Le Boulluec, A. (1981): Clément d'Alexandrie Stromate V, Les Éditions du Cerf, Paris.

Ricciardelli, G. (2000): Inni orfici, Mondadori, Milano.

Sfameni Gasparro, G. (2015): «Demonic Power», en E. Eidinow - J. Kindt (eds.), Oxford Handbook of Greek Religion, University Press, Oxford, pp. 413-427.

SuÁreZ De la Torre, E. 2000: «La noción de daimon en la literatura de la Grecia Arcaica y Clásica», en A. Pérez Jiménez - G. Cruz Andreotti (eds.), Seres intermedios (ángeles, demonios y genios en el mundo mediterráneo), Ediciones Clásicas, Madrid, pp. 47-87.

West, M. L. (1983): The Orphic Poems, Clarendon Press, Oxford. 